\title{
The challenge of comorbidity in clinical trials for multiple sclerosis OPEN
}

Ruth Ann Marrie, MD, $\mathrm{PhD}$

Aaron Miller, MD

Maria Pia Sormani, PhD

Alan Thompson, MD

Emmanuelle Waubant, MD, PhD

Maria Trojano, MD

Paul O'Connor, MD, $\mathrm{MSc}$

Stephen Reingold, PhD Jeffrey A. Cohen, MD

For the attendees of the International Workshop on Comorbidity in Multiple Sclerosis

Correspondence to Dr. Marrie: rmarrie@hsc.mb.ca

\section{See page 1446}

Supplemental data at Neurology.org

\section{ABSTRACT}

Objective: We aimed to provide recommendations for addressing comorbidity in clinical trial design and conduct in multiple sclerosis (MS).

Methods: We held an international workshop, informed by a systematic review of the incidence and prevalence of comorbidity in MS and an international survey about research priorities for studying comorbidity including their relation to clinical trials in MS.

Results: We recommend establishing age- and sex-specific incidence estimates for comorbidities in the MS population, including those that commonly raise concern in clinical trials of immunomodulatory agents; shifting phase III clinical trials of new therapies from explanatory to more pragmatic trials; describing comorbidity status of the enrolled population in publications reporting clinical trials; evaluating treatment response, tolerability, and safety in clinical trials according to comorbidity status; and considering comorbidity status in the design of pharmacovigilance strategies.

Conclusion: Our recommendations will help address knowledge gaps regarding comorbidity that interfere with the ability to interpret safety in monitored trials and will enhance the generalizability of findings from clinical trials to "real world" settings where the MS population commonly has comorbid conditions. Neurology ${ }^{\circledR}$ 2016;86:1437-1445

\section{GLOSSARY}

MS = multiple sclerosis; PRECIS = Pragmatic-Explanatory Continuum Index Summary.

In 2005, more than 130 million Americans had one or more chronic health conditions. ${ }^{1}$ Such findings are not restricted to North America. ${ }^{2}$ Many individuals with a chronic disease will have another coexisting (comorbid) condition, and the likelihood of comorbidity increases with age. Comorbidity refers to the total burden of (chronic) illness other than the specific disease of interest. ${ }^{3}$ Multimorbidity refers to the co-occurrence of 2 or more chronic conditions in an individual; it does not emphasize a specific index condition. ${ }^{4}$

Physical (medical) and psychiatric comorbidities are common in multiple sclerosis (MS). ${ }^{5}$ Recent reviews suggest that the most common medical comorbidities in MS are hypertension, hyperlipidemia, and chronic lung disease while the most common psychiatric comorbidities are depression and anxiety. ${ }^{5}$ Several studies suggest that comorbidity is associated with disability progression, lesion accrual on MRI, lower quality of life, hospitalizations, and mortality. ${ }^{6-9}$

However, little is known about how comorbidities influence MS-related treatment, including the decision to treat, the choice of agent, or treatment effectiveness, safety, tolerability, and

\footnotetext{
From the Departments of Internal Medicine (R.A.M.) and Community Health Sciences (R.A.M.), University of Manitoba, Winnipeg, Canada; Icahn School of Medicine at Mount Sinai (A.M.), New York, NY; Biostatistic Unit (M.P.S.), Department of Health Sciences, University of Genova, Italy; Faculty of Brain Sciences (A.T.), University College London, UK; University of California San Francisco (E.W.); Department of Basic Medical Sciences, Neurosciences and Sense Organs (M.T.), University of Bari, Italy; St. Michael's Hospital (P.O.), Toronto, Canada; Scientific and Clinical Review Associates, LLC (S.R.), Salisbury, CT; and Mellen Center for MS Treatment and Research (J.A.C.), Cleveland Clinic, OH. International Workshop on Comorbidity in Multiple Sclerosis coinvestigators are listed on the Neurology ${ }^{\circledR}$ Web site at Neurology.org. Go to Neurology.org for full disclosures. Funding information and disclosures deemed relevant by the authors, if any, are provided at the end of the article. The Article Processing Charge was paid by the National Multiple Sclerosis Society and the European Committee for Treatment and Research in Multiple Sclerosis.

This is an open access article distributed under the terms of the Creative Commons Attribution-NonCommercial-NoDerivatives License 4.0 (CC BY-NC-ND), which permits downloading and sharing the work provided it is properly cited. The work cannot be changed in any way or used commercially.
} 
adherence. Therefore, an international group of investigators in MS, epidemiology, clinical trials, and comorbidity met in Toronto, Canada, March 27 and 28, 2015, under the auspices of the International Advisory Committee on Clinical Trials in Multiple Sclerosis and sponsored by the European Committee for Treatment and Research in Multiple Sclerosis and the US National Multiple Sclerosis Society. This report describes the discussions and recommendations for addressing comorbidity in the context of clinical trial design and conduct in MS. We considered the effect of comorbidity on treatment in MS, eligibility for clinical trials, safety monitoring, and ethical issues.

EFFECT OF COMORBIDITY ON TREATMENT OF MS Literature regarding the effect of comorbidity on treatment of MS is limited. Findings in other chronic diseases suggest that comorbidity may affect multiple aspects of treatment. First, comorbidity may impede care. Individuals affected by multimorbidity report multiple barriers to self-care, including the compound effects of medications, difficulties in coordinating multiple medications, the total burden of medications, and financial challenges. ${ }^{10}$ Second, comorbidity may affect the frequency or intensity of treatment of coexisting conditions. ${ }^{11-14}$ Third, comorbidity may affect persistence or adherence (defined in Ref. 15) to treatment, further reducing the benefits of therapies, which are only partially effective. For example, depressed individuals with diabetes are 1.5 -fold less likely to persist with pharmacotherapy for diabetes after 12 months of follow-up than nondepressed individuals. ${ }^{16}$ Although the effect of comorbidity on persistence with MS disease-modifying therapies is unknown, depression is associated with reduced adherence to disease-modifying therapy (odds ratio 0.55 ; $0.42-$ 0.74). ${ }^{17}$ Findings on whether adherence improves after treatment of depression are inconsistent. ${ }^{17,18}$ Fourth, comorbidity may affect the effectiveness, safety, and tolerability of treatment, although evidence for these issues is limited in MS. In a secondary analysis of longitudinal data from a randomized controlled trial of a teleconferencedelivered fatigue management intervention for MS, comorbid diabetes or arthritis modified the response to the intervention. Individuals with diabetes improved more slowly after intervention than those without diabetes, while individuals with arthritis improved more rapidly than those without arthritis but they had difficulty sustaining improvements. ${ }^{19}$ Finally, comorbidity may increase the risk of drugdrug and drug-disease interactions.
COMORBIDITY AND ELIGIBILITY FOR CLINICAL TRIALS Individuals with comorbidities frequently are underrepresented in clinical trials. ${ }^{20}$ Therefore, trial findings may not apply to a typical clinic population with comorbidities. Boyd et al. ${ }^{20}$ reviewed clinical trials identified using Cochrane reviews for diabetes, heart failure, chronic obstructive pulmonary disease, and stroke. These trials frequently excluded individuals with comorbidities, ranging from $0 \%$ to $44 \%$ of diabetes trials, $0 \%$ to $42 \%$ of heart failure trials, $0 \%$ to $55 \%$ of chronic obstructive pulmonary disease trials, and $0 \%$ to $39 \%$ of stroke trials. Moreover, only $43.5 \%$ (70/161) of the trials reported the prevalence of any comorbidity among participants. Information regarding the definition or ascertainment of comorbidity was limited. Only 3.1\% (5/161) of trials used comorbidity as a subgroup variable. A review of randomized trials published in the 5 highest-impact general medical journals and specialized journals that focused on the most prevalent chronic conditions found that multimorbidity affected participant eligibility in 95\% of trials. ${ }^{21}$ Individuals with multimorbidity were excluded in $63 \%$ of the trials examined; this did not change from 1995 to 2010 . Only $2.1 \%$ of trials explicitly included individuals with multimorbidity. A systematic review of 26 trials or prospective observational studies in cardiovascular disease focused on comorbidity measurement. ${ }^{22}$ The comorbidities assessed varied across studies and were assessed using varied data sources with $35 \%$ not reporting the data source.

The situation is similar in MS where most pharmacologic trials exclude individuals with severe comorbidities or substance use disorders. ${ }^{23-26} \mathrm{We}$ reviewed the published results of 9 sentinel placebocontrolled trials of disease-modifying therapies approved for MS in the United States (table 1). ${ }^{23-31}$ Five of 9 trials $(55.6 \%)$ excluded individuals with various comorbidities. In 4 of those 5 trials, the description of the exclusions for comorbidities was vague, ${ }^{25,29-31}$ making it unclear how they were operationalized. Uniformly, the way in which comorbidity was assessed for the purposes of eligibility was not reported. None of the trials described the comorbidity status of participants at enrollment. Furthermore, none considered the presence of comorbidity as a subgroup variable for a priori or post hoc analyses.

Although we did not review all clinical trials of nonpharmacologic interventions for managing symptoms of MS, an ongoing systematic review of comorbidity measurement in randomized trials of rehabilitation interventions suggests that comorbidities are only considered in relation to exclusion criteria and are rarely reported when participant characteristics are described (M. Finlayson, personal communication, 2015). For example, Oken et al. ${ }^{32}$ 
Table 1 Consideration of comorbidities in phase III placebo-controlled sentinel trials of disease-modifying therapies in MS

\begin{tabular}{|c|c|c|c|c|c|c|c|}
\hline Author & Year & Trial name & Agent & $\begin{array}{l}\text { Age } \\
\text { range, y }\end{array}$ & Comorbidities excluded & $\begin{array}{l}\text { Comorbidities } \\
\text { reported as } \\
\text { characteristics of } \\
\text { study population }\end{array}$ & $\begin{array}{l}\text { Comorbidities reported as } \\
\text { adverse events }\end{array}$ \\
\hline IFNB $^{23}$ & 1993 & & $\begin{array}{l}\text { Interferon- } \\
\beta-1 b\end{array}$ & $18-50$ & None stated & None & Cardiac arrhythmia \\
\hline Johnson ${ }^{24}$ & 1995 & & $\begin{array}{l}\text { Glatiramer } \\
\text { acetate }\end{array}$ & $18-45$ & $\begin{array}{l}\text { IDDM, positive HIV or HTLV-I serology, } \\
\text { evidence of Lyme disease, required use } \\
\text { of NSAIDs or aspirin during trial }\end{array}$ & None & \\
\hline Jacobs $^{25}$ & 1996 & MSCRG & $\begin{array}{l}\text { Interferon- } \\
\beta-1 a\end{array}$ & $18-55$ & $\begin{array}{l}\text { Conditions other than MS compromising } \\
\text { organ function }\end{array}$ & None & Depression \\
\hline Hartung 26 & 2002 & MIMS & Mitoxantrone & $18-55$ & None stated & None & Arrhythmia \\
\hline Polman ${ }^{28}$ & 2006 & AFFIRM & Natalizumab & $18-50$ & None stated & None & Melanoma \\
\hline O'Connor $^{30}$ & 2011 & TEMSO & Teriflunomide & $18-55$ & Other systemic diseases & None & Hypertension \\
\hline Gold $^{31}$ & 2012 & DEFINE & $\begin{array}{l}\text { Dimethyl } \\
\text { fumarate }\end{array}$ & $18-55$ & $\begin{array}{l}\text { Another major disease that would } \\
\text { preclude participation in a clinical trial }\end{array}$ & None & Neoplasms (renal failure) \\
\hline
\end{tabular}

Abbreviations: AV = atrioventricular; HTLV-I = human T-lymphotropic virus 1; IDDM = insulin dependent diabetes mellitus; MS = multiple sclerosis; NSAID = nonsteroidal anti-inflammatory drug.

randomized patients with MS to a weekly yoga class, weekly exercise class using a stationary bicycle, or a waiting-list control group. Participants with insulindependent diabetes; symptomatic lung disease; uncontrolled hypertension; liver or kidney failure; alcoholism/drug abuse; symptoms or signs of congestive heart failure, ischemic heart disease, or symptomatic valvular disease; or corrected visual acuity worse than 20/50 binocularly were excluded. A controlled trial of physiotherapy as intervention to improve mobility in MS excluded individuals with other major general medical or surgical disorders. ${ }^{33}$

While exclusion of participants with comorbidities is intended to ensure participant safety, the consequence is that we lack knowledge about the safety, tolerability, and efficacy of the studied regimens in persons with MS who have common comorbidities. Limited data suggest that safety and tolerability of disease-modifying therapies are affected by comorbidity. An observational study found that individuals with migraine have more difficulty tolerating interferon- $\beta$ because of worsening headache profiles. ${ }^{34}$ The risk of fingolimod-associated macular edema is higher among individuals with comorbid diabetes. ${ }^{35}$ These issues are particularly important for future trials in progressive MS, in which the target population is likely to be older and, therefore, more likely to have comorbidity. Excluding individuals with comorbidities in these trials slows accrual and produces a study population that is even more divergent from clinical populations than trials conducted in relapsing-remitting MS.
EXPLANATORY VS PRAGMATIC TRIALS Randomized clinical trials can be classified as explanatory or pragmatic (table 2). ${ }^{36}$ Explanatory trials test the efficacy of an intervention, that is, the effects under ideal conditions. An effort is made to enhance the internal validity of the trial by achieving a more homogeneous study population with well-specified inclusion and exclusion criteria, and by controlling all aspects of the intervention and comparator. In contrast, pragmatic trials test the effectiveness of an intervention, that is, the effects in real-world clinical settings where populations are more heterogeneous and differ from those in explanatory trials. Therefore, pragmatic trials produce findings that are potentially more generalizable and applicable to clinical practice. Clinical trials in MS to date largely have been explanatory in nature.

Although this classification suggests trials fall into distinct groups, explanatory and pragmatic trials really exist on a continuum, and several aspects or domains of a trial's design may influence where it falls in the continuum. ${ }^{37}$ These may include eligibility criteria, the flexibility of the experimental and comparison interventions, required investigator expertise, choice of outcomes, intensity of follow-up and ascertainment of outcomes, and measures to ensure and assess adherence to the interventions by the participants and practitioners. ${ }^{37}$ The Pragmatic-Explanatory Continuum Index Summary (PRECIS) tool and its subsequent revision (PRECIS-2) ${ }^{38,39}$ were developed to assist trialists in considering these factors when designing their trials with the goal of matching 
Table 2 Comparison of explanatory and pragmatic clinical trials

Explanatory
Test efficacy: Does this intervention work under ideal
conditions?
High internal validity at possible expense of external validity
Largely phase II-III
Smaller sample size
Controlled environment
Emphasize homogeneity of population and intervention, e.g.
Restrictive inclusion/exclusion criteria
Instructions about applying intervention strict for all
components
Select highly experienced practitioners
Outcomes focus on measurable symptoms or markers
Shorter but intense follow-up
Adherence of participants and practitioners carefully assessed
Intention-to-treat analysis, possibly supplemented by
per-protocol analysis

designs to the intended uses of the trial results. The tool could also be used to evaluate existing trials (for a more detailed description of PRECIS-2, see appendix e-1 on the Neurology ${ }^{\circledR}$ Web site at Neurology.org).

Pragmatic trials face challenges. Because the intervention(s) is not as tightly controlled, it may not be as well delivered, reducing its benefit. Increased heterogeneity and the dilution of the intervention's effect require larger sample sizes (discussed further in Ref. 40) and longer follow-up time, increasing costs and the risk of attrition. Although a pragmatic trial may be performed in multiple clinical settings, we cannot assume that the findings from one clinical setting translate to other clinical settings. Nonetheless, relaxing criteria regarding age and comorbidity status could enroll a population more similar to that seen in clinic settings.

COMORBIDITY AND SAFETY MONITORING IN CLINICAL TRIALS All clinical trials need safety monitoring. Typically, large randomized, multisite studies such as those used to evaluate diseasemodifying therapies establish a Data Safety Monitoring Committee, which reviews trial conduct and accumulating data and advises the study sponsor regarding the ongoing safety of the trial participants. When participants experience treatment emergent adverse events including comorbidities such as hypertension, the Data Safety Monitoring Committee must decide whether the observed events are occurring at a rate greater than expected and whether they are treatment-related (i.e., a true safety signal) or not. Understanding how adverse events may affect differentially those with comorbidity is also important.

\section{Pragmatic}

Test effectiveness: Does this intervention work under usual conditions?

Improved external validity

Largely phase IV

Larger sample size (to increase power to detect small effects)

Full spectrum of routine clinical settings

Emphasize heterogeneity of population and intervention, e.g.

All participants enrolled regardless of expected risk, comorbidities, adherence

Instructions about applying intervention flexible

Include practitioners with range of skills

Spectrum of outcomes, largely patient-centered

Longer, less intense follow-up

Adherence is assessed minimally or not at all

All patients

For common adverse events, the observed event rates can simply be compared between intervention groups, that is, using data internal to the trial. However, for rare (i.e., with a low event rate), serious adverse events such as cancers, the use of external comparators is needed. Such assessments require a good understanding of the expected age- and sexspecific incidence of comorbidities in the (untreated) MS population as these may differ from the rates reported for the general population. However, a recent systematic review identified very few studies evaluating the incidence of comorbidity in MS, with even fewer being population-based. ${ }^{5}$ The most commonly studied conditions were cancer and epilepsy; however, the time period over which incidence was being studied was often unclear, the definition of the conditions varied across studies, and age- and sex-specific estimates were not generally reported. Thus, the information necessary to assess the significance of rare but clinically important adverse events is largely lacking.

Often it is not until a drug is released to the market that it is used in a significant number (if any) of individuals with comorbidities, and this is when adverse effects specific to individuals with comorbidity may be detected. However, postapproval, safety is not monitored as systematically at the individual or group level as in clinical trials. Although the strategies used for postmarketing surveillance vary somewhat across nations ${ }^{41}$ the challenges faced are similar. Postmarketing surveillance may involve one or more components including passive reporting of adverse drug reactions, active pharmacovigilance, phase IV studies, and the use of research networks to evaluate specific 
adverse events of interest. Passive reporting systems underreport adverse drug reactions by as much as $98 \%$ as compared to systematic monitoring, and phase IV studies may not be completed as requested. ${ }^{41}$ Specific efforts are required to assess the safety of new therapies in individuals with MS and comorbidities in the postmarketing phase.

ETHICAL ISSUES Consideration of whether to include or exclude participants with comorbidity in a clinical trial illustrates a potential conflict in ethical principles inherent in clinical trials. Because the lifetime prevalence of comorbidity in patients with MS is substantial, this issue is frequently encountered in MS trials. Expanding the age of enrolled participants and including those with comorbidities are ways to make the study population more typical. However, such individuals may have decreased likelihood of benefiting (i.e., violation of the ethical principle of beneficence) and an elevated risk of adverse effects (i.e., violation of the principle of nonmaleficence). There also may be concern that inclusion of participants with comorbidity may complicate interpretation of the trial if, for example, they adhere less well to assigned treatment or differentially discontinue treatment or trial participation prematurely.

These considerations are potentially in conflict with the principle of autonomy that states that unless the safety concerns are more than hypothetical, informed patients should have the opportunity to participate. Moreover, the external validity (generalizability) of the study is reduced if the trial population does not represent the clinical population in whom the therapy will be used. From an ethical perspective, the principle of justice suggests that particular individuals should not bear a disproportionate burden of research participation, nor should they be unfairly excluded from the potential benefits of participation. Thus, excluding individuals with MS from clinical trials solely on the basis of age or comorbidity status requires careful consideration of the reasons and ramifications.

RECOMMENDATIONS The workshop produced several recommendations to address knowledge gaps regarding the incidence of comorbidity that may interfere with the ability to assess safety in monitored trials, and the limited generalizability of clinical trials to clinical settings where the MS population commonly has comorbid conditions. These are described generally below and summarized in table 3 in more detail for the most common comorbidity, psychiatric comorbidity.

Establish age- and sex-specific incidence estimates for comorbidities in the MS population, including those that commonly raise concern in clinical trials of MS diseasemodifying therapies. Comorbidities prioritized for future incidence studies were depression, anxiety, autoimmune disease, diabetes, cancer, hypertension, and migraine, based on several considerations. First, they may affect clinician-assessed, patient-reported, and imaging outcomes in MS, and health care utilization. ${ }^{6-9,42}$ Second, they may affect adherence to treatment. ${ }^{17}$ Third, they may affect the frequency or severity of adverse events. ${ }^{35}$ Fourth, they may be

\section{Table $3 \quad$ Addressing psychiatric comorbidity in clinical trials for multiple sclerosis}

Issues and strategies

1. Establish age- and sex-specific incidence estimates for depression and anxiety

2. For all clinical trial participants, report the severity of depression and anxiety symptoms using a validated tool and report histories of clinician-diagnosed depression and anxiety at baseline and at the end of the clinical trial

3. Obtain a preliminary assessment of the safety of the intervention of interest in persons with comorbid depression and anxiety e.g., In phase II clinical trials, evaluate whether the intervention of interest worsens depression/anxiety symptoms using a validated tool (i.e., make this one of the relevant safety signals)

4. Based on phase II trials, consider inclusion of persons with depression and anxiety in phase III trials

e.g., If no safety concerns in phase II trials, allow inclusion of such individuals in phase III clinical trials unless the individual is suicidal or so mentally ill that participation is deemed to place the person at significant risk per the health care providers most responsible for managing their mental health

5. Ensure appropriate access to mental health care during the trial as needed

6. Monitor adherence of study participants to the intervention and evaluate whether this differs by psychiatric comorbidity status

7. Evaluate treatment response, tolerability, and safety according to psychiatric comorbidity status, as defined based on the lifetime history of psychiatric comorbidity and severity of depression and/or anxiety at enrollment

8. If sample size is thought to be a concern because of the inclusion of participants with depression or anxiety who may have heterogeneous responses or may be less likely to adhere to the intervention, investigators could set a threshold for the proportion of depressed/anxious persons who could be enrolled in the trial, as higher proportions of persons with comorbidities that may contribute to heterogeneity will increase required sample sizes ${ }^{40}$

9. Ensure that phase IV studies enroll persons with multiple sclerosis who are depressed or anxious and evaluate whether their risk of adverse events differs from that reported in phase III trials. The use of concomitant medications should be considered in these analyses 
identified as adverse events in clinical trials; cancer and autoimmune disease were of particular interest in this regard. ${ }^{43,44}$ Discussants also noted the importance of considering health behaviors such as smoking and obesity, as they are associated with the risk of developing comorbidities and may have independent effects on efficacy and safety.

Shift phase III clinical trials of new therapies in MS along the continuum from explanatory to more pragmatic trials. Specifically, we propose changes to eligibility criteria for clinical trials of pharmacologic and nonpharmacologic therapies. First, relax age restrictions. Second, consider relaxing restrictions on the inclusion of individuals with comorbidity. This has been feasible in other fields (table 4). Such decisions are a tradeoff between homogeneity of the population and the strength of the signal being sought, safety, and generalizability of the findings to clinical practice. We suggest that, in the absence of strong a priori safety concerns, individuals with the most common comorbidities in the MS population, ${ }^{5}$ including depression, anxiety, hypertension, hyperlipidemia, and chronic lung disease, be considered for inclusion in trials. Furthermore, individuals with a history of cancer should also be considered as potential participants in some settings. These changes will be particularly important in trials in progressive MS, as these individuals will be older and will have a greater burden of comorbidity. These changes will require larger trials.

The comorbidity status of enrolled clinical trial populations should be clearly and consistently described. The description of clinical trial populations at baseline should include the prevalence of common comorbidities and whether they were currently treated (concomitant medications). These characteristics should also be updated and reported for the trial population as of the last study visit. Also, blood pressure, body mass index, waist-hip ratio, and current symptoms of depression and anxiety should be reported. To facilitate comparison of findings across clinical trials, we propose that, at a minimum, the presence or absence of the following diagnoses be reported: depression, anxiety, hypertension, hyperlipidemia, chronic lung disease (including asthma and chronic obstructive pulmonary disease), diabetes, autoimmune thyroid disease, migraine, and prior cancers. Ideally, these conditions would be verified by review of medical records and would not be based solely on self-report at the time of trial enrollment. For the measurement of current symptoms of depression and anxiety, it would be helpful if a single tool was used consistently in trials. Although several choices exist for depression, less work has validated scales for anxiety. ${ }^{50,51}$ Further evaluation of the responsiveness of available tools in the MS population would assist in identifying the best instrument. A systematic review of the psychometric properties of depression scales is ongoing and may provide guidance. ${ }^{52}$

Evaluate treatment response, tolerability, and safety in clinical trials according to comorbidity status and health behavior status. Based on observational studies showing that comorbidity and health behaviors affect clinician-assessed, patient-reported, and imaging outcomes in $\mathrm{MS},^{7-10,42}$ it is likely that efficacy, safety, and tolerability differ by comorbidity status. This issue needs to be assessed to ensure that individuals with MS are not offered ineffective treatments while incurring risks. The initial focus of such subgroup analyses should focus on common, readily measured comorbidities such as hypertension, diabetes, smoking status, and obesity.

Comorbidity status should be considered in the design of postmarketing pharmacovigilance strategies. Phase IV studies should aim to enroll individuals with comorbidities and evaluate whether their risk of adverse events differs from that reported in phase III trials. The use of concomitant medications should be considered in these analyses. Research networks with access to large databases should be used to conduct studies to specifically assess the risk of significant

\begin{tabular}{|c|c|c|c|}
\hline Table 4 & Examples of pragmatic trials with relaxed eligibility $\mathrm{cr}$ & teria for age or comorbidity & \\
\hline $\begin{array}{l}\text { Trial (name } \\
\text { or lead } \\
\text { author) }\end{array}$ & Question & Eligibility criteria regarding age and comorbidity & Trial registration \\
\hline Price ${ }^{45}$ & $\begin{array}{l}\text { Are leukotriene antagonists equivalent to inhaled } \\
\text { glucocorticoids as first-line management of asthma? }\end{array}$ & $\begin{array}{l}\text { Age } 12-80 \text { y; excluded acute or chronic pulmonary } \\
\text { processes; other comorbidities allowed }\end{array}$ & $\begin{array}{l}\text { Controlled clinical trials } \\
\text { no. ISRCTN99132811 }\end{array}$ \\
\hline $\begin{array}{l}\text { WHICH? } \\
\text { trial }^{46,47}\end{array}$ & $\begin{array}{l}\text { Is multidisciplinary management of patients with CHF } \\
\text { post-acute hospitalization delivered in a patient's own } \\
\text { home superior to care delivered via a specialist CHF } \\
\text { outpatient clinic? }\end{array}$ & $\begin{array}{l}\text { Age } \geq 18 \text { y; excluded persons with a terminal condition } \\
\text { likely to result in death or hospitalization within } 12 \text { mo }\end{array}$ & $\begin{array}{l}\text { Australian New Zealand } \\
\text { clinical trials registry no. } \\
12607000069459\end{array}$ \\
\hline $\begin{array}{l}\text { DRESS } \\
\text { study } 48,49\end{array}$ & $\begin{array}{l}\text { Is TNF blocker dose reduction noninferior to usual care with } \\
\text { regard to persistent disease flare in rheumatoid arthritis? }\end{array}$ & $\begin{array}{l}\text { Only exclude persons with comorbidity if it also requires } \\
\text { treatment with anti-TNF agents (e.g., Crohn disease) or } \\
\text { when it is expected that the outcome cannot be measured } \\
\text { (e.g., short life expectancy, planned major surgery) }\end{array}$ & $\begin{array}{l}\text { Dutch trial register } \\
\text { NTR3216 }\end{array}$ \\
\hline
\end{tabular}

Abbreviations: $\mathrm{CHF}=$ chronic heart failure; TNF $=$ tumor necrosis factor. 
adverse events in individuals with comorbidities who use new therapies. The use of registries of all individuals using a novel therapy also may be helpful.

CONCLUSION Comorbidity is common in the MS population and affects safety and benefit of pharmacologic and nonpharmacologic therapies, including those being tested in clinical trials. The eligibility criteria used in trials that restrict participants based on comorbidities are a tradeoff between homogeneity of the population and the strength of the signal being sought, safety, and generalizability of the findings. The proposed recommendations are intended to allow clinical trials to better inform use of MS therapies in clinical practice.

\section{AUTHOR CONTRIBUTIONS}

The corresponding author (R.A.M.) takes responsibility for the integrity of the data and the accuracy of the data analysis. Ruth Ann Marrie drafted the manuscript. All authors revised the manuscript and approved the final version to be published.

\section{STUDY FUNDING}

Funded in part by the National Multiple Sclerosis Society (US), ECTRIMS, a Don Paty Career Development Award from the MS Society of Canada (to R.A.M.), and a Manitoba Research Chair from Research Manitoba (to R.A.M.). The funding source(s) had no role in the study design, collection, analysis, or interpretation of the data, or in the decision to submit the article for publication. The International Conference on Comorbidity in Multiple Sclerosis was organized under the auspices of the International Advisory Committee on Clinical Trials in Multiple Sclerosis. The conference and the activities of the committee were funded by the European Committee for Treatment and Research in Multiple Sclerosis and the US National Multiple Sclerosis Society.

\section{DISCLOSURE}

R. Marrie receives research funding from the Canadian Institutes of Health Research, Public Health Agency of Canada, Manitoba Health Research Council, Health Sciences Centre Foundation, Multiple Sclerosis Society of Canada, Multiple Sclerosis Scientific Foundation, and Rx \& D Health Research Foundation, and has conducted clinical trials funded by Bayer Inc. and Sanofi-Aventis. A. Miller has received research support from Novartis, Genentech, Genzyme, Sanofi-Aventis, Biogen Idec, Roche, and Mallinckrodt (Questcor), personal consulting fees from Genzyme/Sanofi-Aventis, Biogen Idec, GlaxoSmithKline, EMD Serono (Merck Serono), Mallinckrodt, Novartis, Acorda, Accordant Health Services, Teva, Roche, Alkermes, Genentech, and Caremark (Accordan Health Care), and speaker honoraria from Biogen Idec (unbranded disease awareness programs only). M. Sormani received consultation fees from Biogen, Novartis, Merck Serono, Teva, Genzyme, Roche, and Synthon. A. Thompson has received honoraria/support for travel for consultancy from Biogen Idec, MedDay, Eisai, and Novartis, and for teaching from EXCEMED, Novartis, and Teva. He receives an honorarium from Sage Publications as editor in chief of Multiple Sclerosis Journal. E. Waubant receives research funding from the NIH, the NMSS, and the Race to Erase MS. She has received honorarium for one educational lecture from Genentech. She volunteers on an advisory board for a Novartis trial. She has received honorarium or travel support from ACTRIMS, ECTRIMS, and the AAN. M. Trojano has served on scientific advisory boards for Biogen Idec, Novartis, and Genzyme; has received speaker honoraria from Biogen Idec, Sanofi-Aventis, Merck Serono, Teva, Novartis, and Almirall; has received research grants for her institution from Biogen Idec, Merck Serono, and Novartis. P. O'Connor reports no disclosures relevant to the manuscript. S. Reingold reports personal consulting fees from the National Multiple Sclerosis Society (NMSS) and the European Committee for Treatment and Research in Multiple
Sclerosis (ECTRIMS), during the conduct of this work, and personal consulting fees from Bayer HealthCare, Biogen Idec, Coronado Biosciences Inc., the Cleveland Clinic Foundation, Eli Lilly and Company, from EMD Serono and Merck Serono, Genentech, F. Hoffmann-La Roche, Ironwood Pharmaceuticals Inc., ISIS Pharmaceuticals Inc., MedImmune Inc., Novartis Pharmaceuticals Corporation, Observatoire Français de la Sclérosis en Plaques, Opexa Therapeutics, Sanofi-Aventis, SK Biopharmaceuticals, Synthon Pharmaceuticals Inc., TEVA Pharmaceutical Industries, and Fondation pour l'aide à la Recherche sur la Sclérosis en Plaques, for activities outside of this work. J. Cohen reports personal compensation for consulting from EMD Serono, Genentech, Genzyme, Innate Immunotherapeutics, Novartis, and Vaccinex. Dr. Cohen receives research support paid to his institution from Biogen Idec, Consortium of MS Centers, US Department of Defense, Genzyme, US NIH, National MS Society, Novartis, Receptos, Synthon, Teva, and Vaccinex. Go to Neurology.org for full disclosures.

Received August 30, 2015. Accepted in final form December 1, 2015.

\section{REFERENCES}

1. National Center for Chronic Disease Prevention and Health Promotion. Chronic Diseases: The Power to Prevent, the Call to Control. Hyattsville, MD: Centers for Disease Control; 2009.

2. Caughey G, Vitry A, Gilbert A, Roughead E. Prevalence of comorbidity of chronic diseases in Australia. BMC Public Health 2008;8:221.

3. Gijsen R, Hoeymans N, Schellevis FG, Ruwaard D, Satariano WA, van den Bos GA. Causes and consequences of comorbidity: a review. J Clin Epidemiol 2001;54: 661-674.

4. Valderas JM, Starfield B, Sibbald B, Salisbury C, Roland M. Defining comorbidity: implications for understanding health and health services. Ann Fam Med 2009; 7:357-363.

5. Marrie RA, Reider N, Cohen J, et al. A systematic review of the incidence and prevalence of comorbidity in multiple sclerosis: overview. Mult Scler J 2015;21:263-281.

6. Marrie RA, Elliott L, Marriott J, Cossoy M, Tennakoon A, $\mathrm{Yu}$ N. Comorbidity increases the risk of hospitalizations in multiple sclerosis. Neurology 2015;84:350-358.

7. Weinstock-Guttman B, Zivadinov R, Mahfooz N, et al. Serum lipid profiles are associated with disability and MRI outcomes in multiple sclerosis. J Neuroinflammation 2011;8:127.

8. Tettey P, Simpson S, Taylor B, et al. An adverse lipid profile is associated with disability and progression in disability, in people with MS. Mult Scler J 2014;20: 1737-1744.

9. Warren SA, Turpin KV, Pohar SL, Jones CA, Warren KG. Comorbidity and health-related quality of life in people with multiple sclerosis. Int J MS Care 2009;11:6-16.

10. Bayliss EA, Steiner JF, Fernald DH, Crane LA, Main DS. Descriptions of barriers to self-care by persons with comorbid chronic diseases. Ann Fam Med 2003;1:15-21.

11. Ani C, Bazargan M, Hindman D, Bell D, Rodriguez M, Baker RS. Comorbid chronic illness and the diagnosis and treatment of depression in safety net primary care settings. J Am Board Fam Med 2009;22:123-135.

12. Redelmeier DA, Tan SH, Booth GL. The treatment of unrelated disorders in patients with chronic medical diseases. N Engl J Med 1998;338:1516-1520.

13. Rost K, Nutting P, Smith J, Coyne JC, Cooper-Patrick L, Rubenstein L. The role of competing demands in the treatment provided primary care patients with major depression. Arch Fam Med 2000;9:150-154. 
14. Nuyen J, Spreeuwenberg PM, Van Dijk L, den Bos GAMV, Groenewegen PP, Schellevis FG. The influence of specific chronic somatic conditions on the care for co-morbid depression in general practice. Psychol Med 2007;38:265-277.

15. Cramer JA, Roy A, Burrell A, et al. Medication compliance and persistence: terminology and definitions. Value Health 2008;11:44-47.

16. Kalsekar ID, Madhavan SS, Amonkar MM, et al. Impact of depression on utilization patterns of oral hypoglycemic agents in patients newly diagnosed with type 2 diabetes mellitus: a retrospective cohort analysis. Clin Ther 2006; 28:306-318.

17. Tarrants M, Oleen-Burkey M, Castelli-Haley J, Lage MJ. The impact of comorbid depression on adherence to therapy for multiple sclerosis. Mult Scler Int 2011;2011:271321.

18. Mohr DC, Goodkin DE, Likosky W, Gatto N, Baumann KA, Rudick RA. Treatment of depression improves adherence to interferon beta- $1 \mathrm{~b}$ therapy for multiple sclerosis. Arch Neurol 1997;54:531-533.

19. Finlayson M, Preissner K, Cho C. Impact of comorbidity on fatigue management intervention outcomes among people with multiple sclerosis. Int J MS Care 2013;15:21-26.

20. Boyd CM, Vollenweider D, Puhan MA. Informing evidence-based decision-making for patients with comorbidity: availability of necessary information in clinical trials for chronic diseases. PLoS One 2012;7:e41601.

21. Jadad AR, To MJ, Emara M, Jones J. Consideration of multiple chronic diseases in randomized controlled trials. JAMA 2011;306:2670-2672.

22. Buck HG, Akbar JA, Zhang SJ, Bettger JA. Measuring comorbidity in cardiovascular research: a systematic review. Nurs Res Pract 2013;2013:563246.

23. The IFNB Multiple Sclerosis Study Group. Interferon beta$1 \mathrm{~b}$ is effective in relapsing-remitting multiple sclerosis: I: clinical results of a multicenter, randomized, double-blind, placebo-controlled trial. Neurology 1993;43:655-661.

24. Johnson KP, Brooks BR, Cohen JA, et al. Copolymer 1 reduces the relapse rate and improves disability in relapsing-remitting multiple sclerosis: results of a phase III multicenter, double-blind, placebo-controlled trial. Neurology 1995;45:1268-1276.

25. Jacobs LD, Cookfair DL, Rudick RA, et al. Intramuscular interferon beta-1a for disease progression in relapsing multiple sclerosis. Ann Neurol 1996;39:285-294.

26. Hartung HP, Gonsette R, Konig N, et al. Mitoxantrone in progressive multiple sclerosis: a placebo-controlled, double-blind, randomised, multicentre trial. Lancet 2002; 360:2018-2025.

27. PRISMS Study Group. Randomized double-blind placebo-controlled study of interferon $\beta-1 \mathrm{a}$ in relapsing/remitting multiple sclerosis. Lancet 1998;352:1498-1504.

28. Polman CH, O'Connor PW, Havrdova E, et al. A randomized, placebo-controlled trial of natalizumab for relapsing multiple sclerosis. N Engl J Med 2006;354:899-910.

29. Kappos L, Radue EW, O'Connor P, et al. A placebocontrolled trial of oral fingolimod in relapsing multiple sclerosis. N Engl J Med 2010;362:387-401.

30. O'Connor P, Wolinsky JS, Confavreux C, et al. Randomized trial of oral teriflunomide for relapsing multiple sclerosis. N Engl J Med 2011;365:1293-1303.

31. Gold R, Kappos L, Arnold DL, et al. Placebo-controlled phase 3 study of oral $\mathrm{Bg}-12$ for relapsing multiple sclerosis. N Engl J Med 2012;367:1098-1107.
32. Oken BS, Kishiyama S, Zajdel D, et al. Randomized controlled trial of yoga and exercise in multiple sclerosis. Neurology 2004;62:2058-2064.

33. Wiles CM, Newcombe RG, Fuller KJ, et al. Controlled randomised crossover trial of the effects of physiotherapy on mobility in chronic multiple sclerosis. J Neurol Neurosurg Psychiatry 2001;70:174-179.

34. Patti F, Nicoletti A, Pappalardo A, et al. Frequency and severity of headache is worsened by interferon- $\beta$ therapy in patients with multiple sclerosis. Acta Neurol Scand 2012; 125:91-95.

35. Jain N, Bhatti MT. Fingolimod-associated macular edema: incidence, detection, and management. Neurology 2012; 78:672-680.

36. Patsopoulos NA. A pragmatic view on pragmatic trials. Dialogues Clin Neurosci 2011;13:217-224.

37. Thorpe KE, Zwarenstein $\mathrm{M}$, Oxman $\mathrm{AD}$, et al. A pragmatic-explanatory continuum indicator summary (PRECIS): a tool to help trial designers. J Clin Epidemiol 2009;62:464-475.

38. Loudon K, Treweek S, Sullivan F, Donnan P, Thorpe KE, Zwarenstein M. The PRECIS-2 tool: designing trials that are fit for purpose. BMJ 2015;350:h2147.

39. Loudon K, Zwarenstein M, Sullivan F, Donnan P, Treweek S. Making clinical trials more relevant: improving and validating the PRECIS tool for matching trial design decisions to trial purpose. Trials 2013;14:115.

40. Weiss CO, Varadhan R, Puhan MA, et al. Multimorbidity and evidence generation. J Gen Intern Med 2014;29: 653-660.

41. Wiktorowicz M, Lexchin J, Paterson M, et al. Research Networks Involved in Post-Market Pharmacosurveillance in the United States, United Kingdom, France, New Zealand, Australia, Norway and European Union: Lessons for Canada. Edmonton, Alberta: Patient Safety Institute; 2008.

42. Marrie RA, Rudick R, Horwitz R, et al. Vascular comorbidity is associated with more rapid disability progression in multiple sclerosis. Neurology 2010;74:1041-1047.

43. CAMMS223 Trial Investigators, Coles AJ, Compston DA, et al. Alemtuzumab vs. interferon beta1a in early multiple sclerosis. N Engl J Med 2008;359: 1786-1801.

44. Giovannoni G, Comi G, Cook S, et al. A placebocontrolled trial of oral cladribine for relapsing multiple sclerosis. N Engl J Med 2010;362:416-426.

45. Price D, Musgrave SD, Shepstone L, et al. Leukotriene antagonists as first-line or add-on asthma-controller therapy. N Engl J Med 2011;364:1695-1707.

46. Stewart S, Carrington MJ, Horowitz JD, et al. Prolonged impact of home versus clinic-based management of chronic heart failure: extended follow-up of a pragmatic, multicentre randomized trial cohort. Int J Cardiol 2014; 174:600-610.

47. Stewart S, Carrington MJ, Marwick T, et al. The WHICH? trial: rationale and design of a pragmatic randomized, multicentre comparison of home- vs. clinicbased management of chronic heart failure patients. Eur J Heart Fail 2011;13:909-916.

48. den Broeder A, van Herwaarden N, van der Maas A, et al. Dose reduction strategy of subcutaneous TNF inhibitors in rheumatoid arthritis: design of a pragmatic randomised non inferiority trial, the DRESS study. BMC Musculoskelet Disord 2013;14:299. 
49. van Herwaarden N, van der Maas A, Minten MJM, et al. Disease activity guided dose reduction and withdrawal of adalimumab or etanercept compared with usual care in rheumatoid arthritis: open label, randomised controlled, non-inferiority trial. BMJ 2015; 350:h1389.

50. Watson TM, Ford E, Worthington E, Lincoln NB. Validation of mood measures for people with multiple sclerosis. Int J MS Care 2014;16:105-109.
51. Terrill AL, Hartoonian N, Beier M, Salem R, Alschuler K. The 7-item Generalized Anxiety Disorder Scale as a tool for measuring generalized anxiety in multiple sclerosis. Int J MS Care 2015;17:49-56.

52. Webster R, Hind D, Kaklamanou D, Beever D, Barkham M, Cooper C. The assessment of depression in people with multiple sclerosis: a systematic review of psychometric validation studies. PROSPERO 2014;2014: CRD42014010597. 


\title{
Neurology
}

\author{
The challenge of comorbidity in clinical trials for multiple sclerosis \\ Ruth Ann Marrie, Aaron Miller, Maria Pia Sormani, et al. \\ Neurology 2016;86;1437-1445 Published Online before print February 17, 2016 \\ DOI 10.1212/WNL.0000000000002471
}

This information is current as of February 17, 2016

\section{Updated Information \& Services \\ Supplementary Material}

\section{References}

Citations

Subspecialty Collections

Permissions \& Licensing

Reprints including high resolution figures, can be found at:

http://n.neurology.org/content/86/15/1437.full

Supplementary material can be found at:

http://n.neurology.org/content/suppl/2016/02/18/WNL.0000000000002 471.DC1

http://n.neurology.org/content/suppl/2016/04/09/WNL.0000000000002 471.DC2

This article cites 50 articles, 11 of which you can access for free at: http://n.neurology.org/content/86/15/1437.full\#ref-list-1

This article has been cited by 5 HighWire-hosted articles:

http://n.neurology.org/content/86/15/1437.full\#\#otherarticles

This article, along with others on similar topics, appears in the following collection(s):

All Medical/Systemic disease

http://n.neurology.org/cgi/collection/all_medical_systemic_disease Clinical trials Methodology/study design

http://n.neurology.org/cgi/collection/clinical_trials_methodology_study design

Multiple sclerosis

http://n.neurology.org/cgi/collection/multiple_sclerosis

Information about reproducing this article in parts (figures,tables) or in its entirety can be found online at:

http://www.neurology.org/about/about_the_journal\#permissions

Information about ordering reprints can be found online:

http://n.neurology.org/subscribers/advertise

Neurology ${ }^{\circledR}$ is the official journal of the American Academy of Neurology. Published continuously since 1951, it is now a weekly with 48 issues per year. Copyright @ 2016 American Academy of Neurology. All rights reserved. Print ISSN: 0028-3878. Online ISSN: 1526-632X.

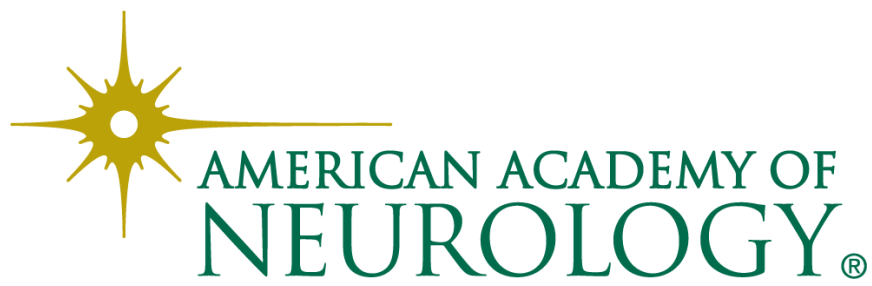

